\title{
Upregulation of NFKBIZ affects bladder cancer progression via the PTEN/PI3K/Akt signaling pathway
}

\author{
TAO XU ${ }^{1 *}$, TING RAO $^{1 *}$, WEI-MING YU ${ }^{1}$, JIN-ZHUO NING $^{1}, \mathrm{XI} \mathrm{YU}^{1}$, \\ SHAO-MING ZHU ${ }^{1}$, KANG YANG ${ }^{1}$, TAO BAI ${ }^{2}$ and FAN CHENG ${ }^{1}$ \\ ${ }^{1}$ Department of Urology, Renmin Hospital of Wuhan University; ${ }^{2}$ Department of Urology, \\ Wuhan No. 1 Hospital, Tongji Medical College, Huazhong University of \\ Science and Technology, Wuhan, Hubei 430060, P.R. China
}

Received January 7, 2021; Accepted March 26, 2021

DOI: $10.3892 /$ ijmm.2021.4942

\begin{abstract}
NF- $\mathrm{KB}$ inhibitor $\zeta$ (NFKBIZ), a member of the I $\mathrm{B}$ family that interacts with $\mathrm{NF}-\kappa \mathrm{B}$, has been reported to be an important regulator of inflammation, cell proliferation and survival. However, the role of NFKBIZ in bladder cancer (BC) remains unknown. The present study aimed to investigate the functions of NFKBIZ in BC. First, the expression levels of NFKBIZ and the associations between NFKBIZ expression and the clinical survival of patients were determined using $\mathrm{BC}$ tissue samples, $\mathrm{BC}$ cell lines and datasets from different databases. Two $\mathrm{BC}$ cell lines (T24 and 5637) were selected to overexpress NFKBIZ, and the proliferative, migratory and invasive abilities of cells were determined; additionally, tumor growth following transplantation in in vivo mouse models was analyzed using T24 cells overexpressing NFKBIZ. Subsequently, the association between NFKBIZ and PTEN was determined using data from databases and immunohistochemistry analysis of clinical and nude mice tumor tissues. Finally, the interactions between NFKBIZ, PTEN and the downstream PI3K/AKT/mTOR signaling pathway were evaluated using western blotting. In conclusion, the present results indicated that NFKBIZ expression was low in BC, and NFKBIZ inhibited the proliferation of BC cells through the PTEN/PI3K/Akt signaling pathway, suggesting that NFKBIZ may represent a novel prognostic biomarker in BC and may provide a potential therapeutic tumor-associated antigen for BC.
\end{abstract}

Correspondence to: Professor Fan Cheng, Department of Urology, Renmin Hospital of Wuhan University, 238 Jiefang Road, Wuchang, Wuhan, Hubei 430060, P.R. China

E-mail: urology1969@163.com

${ }^{*}$ Contributed equally

Key words: bladder cancer, NF- $\kappa \mathrm{B}$ inhibitor $\zeta, \mathrm{PTEN}$, proliferation, migration, invasion

\section{Introduction}

According to global cancer data, bladder cancer (BC) is estimated to be the 9th most common type of cancer worldwide, with $\sim 400,000$ new cases diagnosed annually $(1,2)$. The majority of $\mathrm{BC}$ cases are diagnosed as non-muscle invasive $\mathrm{BC}$ (NMIBC), for which the mortality rate is generally low due to its good prognosis; however, NMIBC often recurs and develops into MIBC (3). MIBC is characterized by rapid metastasis and progression, in addition to poor prognosis, and is the main cause of BC-associated mortality (4-6), with the 5-year overall survival rate being $~ 50 \%$ following surgery (7). Therefore, it remains urgent to identify novel molecular biomarkers and the underlying molecular mechanism of $\mathrm{BC}$ tumorigenesis.

NF- $\kappa B$ can be activated following the stimulation of various types of immune receptors, such as pattern recognition receptors and toll-like receptors, and its activation is controlled by the direct interaction with the IкB inhibitor family (8-10). The most well-established IкB members are the proteins $I \kappa B \alpha, I \kappa B \beta$ and $I \kappa B \varepsilon$, which keep NF- $\kappa B$ in the cytoplasm of unstimulated cells (11). I $\mathrm{KB} \zeta$ is a newly identified I $\mathrm{B}$ family member protein, which is encoded by the NF- $\kappa \mathrm{B}$ inhibitor $\zeta$ (NFKBIZ) gene; it differs from I $\mathrm{KB} \alpha, \mathrm{I} \kappa \mathrm{B} \beta$ and $\mathrm{I} \kappa \mathrm{B} \varepsilon$ as it is atypically localized in the nucleus rather than in the cytoplasm (12). Notably, NFKBIZ has been reported to be an important regulator of inflammation, cell proliferation and survival (12-14). NFKBIZ is induced by toll-like receptor 12 signaling and can coactivate both the canonical and non-canonical NF- $\mathrm{BB}$ signaling pathways (15-17). Polymorphisms and mutations in NFKBIZ are associated with numerous types of disease, including psoriasis, spontaneous skin inflammation, invasive pneumococcal disease and Crohn's disease (18-21); the majority of these diseases are associated with inflammation. Furthermore, NFKBIZ has been associated with cancer. For example, NFKBIZ expression is upregulated in glioma and is associated with a poor prognosis (22). In addition, NFKBIZ expression is downregulated in mycosis fungoides, which is the most common type of primary cutaneous T-cell lymphoma (23). Additionally, it has been demonstrated that tumor formation in NFKBIZ-mutant mice is significantly decreased, and low NFKBIZ expression in human colorectal cancer cells affects 
cell proliferation (24). However, the mechanism underlying the inhibition of tumor growth and whether NFKBIZ can regulate other types of human carcinoma cells has not been elucidated.

Numerous signaling pathways are involved in the occurrence and development of BC. Among them, the PI3K/AKT/mTOR signaling pathway serves a crucial role in the pathogenesis of $\mathrm{BC}$, where it is usually overactivated and plays a central role in stimulating cell proliferation, survival and metastasis (25-28). PTEN is an ubiquitous tumor suppressor that serves an essential role in tumor cell proliferation (25). Notably, PTEN inactivation has been associated with the pathogenesis and development of numerous types of solid tumors, such as colon, gastric and lung cancer (29-31). PTEN inhibits the PI3K/AKT signaling pathway, and a negative feedback association exists between PTEN and phosphorylated (p)-PI3K, indicating that a decrease in p-PI3K expression leads to an increase in PTEN expression (27). Conversely, the loss of PTEN function leads to the overactivation of the PI3K/AKT signaling pathway, which has been demonstrated to accelerate the growth, invasion and metastasis of BC (28). In addition, NF- $\mathrm{KB}$ and PTEN are closely associated in numerous types of cancer, such as colon, gastric and lung cancer (29-31), and NF- $\mathrm{KB}$ is regulated by NFKBIZ.

Therefore, the present study aimed to explore the association between NFKBIZ and PTEN, and whether NFKBIZ can affect the development of BC by regulating PTEN and its downstream PI3K/Akt signaling pathway. The expression levels of NFKBIZ in BC were analyzed, and bioinformatics analysis was used to determine the potential regulatory mechanism and clinical significance of NFKBIZ in BC. In addition, functional experiments were performed to investigate the function of NFKBIZ in BC. The current findings may provide novel insights into the role of NFKBIZ in BC tumorigenesis.

\section{Materials and methods}

Cell culture. The normal urinary tract epithelial cell line (SV-HUC-1) and the BC cell lines (J82, UMUC-3, T24 and 5637) were purchased from The Cell Bank of Type Culture Collection of The Chinese Academy of Sciences. The identification of the $\mathrm{BC}$ cell lines was conducted at the China Centre for Type Culture Collection. SV-HUC-1 cells were cultured in F-12K medium (HyClone; Cytiva) with $10 \%$ fetal calf serum (FCS; HyClone; Cytiva). J82 and UMUC-3 cells were cultured in Minimum Essential Media (HyClone; Cytiva) supplemented with $10 \%$ FCS. T24 and 5637 cells were cultured in RPMI-1640 medium (HyClone; Cytiva) supplemented with $10 \%$ FCS. Cells were maintained in a humidified atmosphere consisting of $5 \% \mathrm{CO}_{2}$ at $37^{\circ} \mathrm{C}$.

Bioinformatics analysis and NFKBIZ expressionprofile mining in The Cancer Genome Atlas (TCGA). Relevant data or figures from TCGA database (http://cancergenome.nih.gov) were downloaded and analyzed using the Gene Expression Profiling Interacting Analysis (GEPIA; http://gepia.cancer-pku.cn), UCSCXena (http://xena.ucsc.edu) and UALCAN (http://ualcan. path.uab.edu) databases. The data from GEPIA included NFKBIZ expression from 404 tumor and 28 adjacent normal control tissues. The data from UCSC Xena included NFKBIZ expression from 407 tumor and 29 adjacent normal control tissues. The data from UALCAN included NFKBIZ expression from 408 tumor and 19 adjacent normal control tissues. NFKBIZ mRNA expression was also explored at different stages, nodal metastasis status and histological subtypes using the UALCAN database. Finally, the 'TCGAbiolinks' package in R language (https://www.rdocumentation.org/packages/TCGAbiolinks/versions/1.2.5) was used to download the mRNA-reads count expression data from TCGA-BLCA, including $408 \mathrm{BC}$ and 19 normal bladder tissue samples. An mRNA expression matrix was made with the raw counts of each RNA in each sample. The 'Deseq2' package in R (http://www. bioconductor.org/packages/release/bioc/html/DESeq2.html) was used to calculate the differential expression of mRNAs between the $\mathrm{BC}$ tissues samples and paracancerous normal specimens. A lfold-changel $>2$ and $\mathrm{P}<0.05$ were used as the threshold values. Survival analysis was performed using these differentially expressed mRNAs using the 'ggsurv' package in $\mathrm{R}$ (https://www.rdocumentation.org/packages/GGally/versions/1.5.0/topics/ggsurv), with $\mathrm{P}<0.05$ used as the screening threshold. The survival curves based on NFKBIZ expression were used to explore the effect of NFKBIZ expression on survival and prognosis of patients with BC. Kaplan-Meier analysis was used for survival analysis, and the log-rank test was used to calculate the P-values.

Chemicals and lentivirus infection. Matrigel was purchased from BD Biosciences and the PTEN inhibitor, VO-OHpic trihydrate (VO), was obtained from MedChemExpress. The treatment condition of $\mathrm{VO}$ was $35 \mathrm{nM} / \mathrm{l}$ at room temperature for $24 \mathrm{~h}$. A lentiviral expression vector (pLV-NFKBIZ) [OBiO Technology (Shanghai) Corp., Ltd.] was used for NFKBIZ gene (NM_031419.4) delivery and stable overexpression. The MOI used to infect T24 and 5637 cells was 40 and 20, respectively. T24 and 5637 cells $\left(1 \times 10^{5}\right)$ were seeded in 6-well plates and grown to $\sim 50 \%$ confluency. Subsequently, the culture medium was removed, and fresh culture medium containing lentiviral carrying NFKBIZ cDNA or a negative control was added according to the MOI. The cells were cultured in an incubator at $37^{\circ} \mathrm{C}$ with $5 \% \mathrm{CO}_{2}$ for $18 \mathrm{~h}$. Next, the culture medium was removed and replaced with fresh medium. After $48 \mathrm{~h}$, culture medium containing $50 \mu \mathrm{g} / \mathrm{ml}$ puromycin (Sigma-Aldrich; Merck KGaA) was added to remove any non-transfected cells. The surviving cell clones were selected and expanded. The lentiviruses were designated as pcDNA-NFKBIZ (pSLenti-EF 1a-EGFP-P2A-Puro-CMV-NFKBIZ-3Flag). The empty vector was used as a negative control (pcDNA-vector; pSLenti-EFla-E GFP-P2A-Puro-CMV-MCS-3Flag). Fluorescence microscopy (magnification, x40; IX73; Olympus Corporation) and western blotting were used to evaluate infection efficiency.

Patient tissues. A total of 34 pairs of fresh BC and adjacent tissue specimens ( $>5 \mathrm{~cm}$ from the tumor) were obtained from patients (25 males and 9 females) with a median age of 65 years (range, 46-79 years) with BC who were diagnosed by the Pathology Department of The Renmin Hospital of Wuhan University (Wuhan, China) between July 2019 and December 2019. A small part of the resected tissue was removed within $30 \mathrm{~min}$ of surgical resection. The removed tissue was divided into two parts: A part of the tissue was 
washed with saline and then fixed with $4 \%$ paraformaldehyde (Beyotime Institute of Biotechnology) for $48 \mathrm{~h}$ at room temperature for paraffin embedding, and another part of the removed tissue was rapidly frozen in liquid nitrogen $\left(-196^{\circ} \mathrm{C}\right)$ and stored at $-80^{\circ} \mathrm{C}$ until required for RNA extraction. Most of the remaining resected tissues were sent to the pathology department for further diagnosis. BC was defined by two pathologists. The tumor stage and grade of all patients were diagnosed according to the 2009 TNM staging system and the 2004 World Health Organization grading system $(32,33)$, respectively. All patients provided written informed consent and the research protocols were approved by the Research Ethics Committee of Renmin Hospital of Wuhan University (approval no. WDRY2019-K035).

Reverse transcription-quantitative PCR (RT-qPCR). Total RNA was extracted from BC samples using TRIzol ${ }^{\circledR}$ reagent (Invitrogen; Thermo Fisher Scientific, Inc.) and reverse transcribed into cDNA using a RevertAid First Strand cDNA Synthesis kit (Thermo Fisher Scientific, Inc.) according to the manufacturer's protocol. qPCR was subsequently performed using a SYBR Green mix (Takara Bio, Inc.), at a final volume of $20 \mu \mathrm{l}$, on an ABI 7500 Real-Time PCR Detection system (Applied Biosystems; Thermo Fisher Scientific, Inc.). The following primer sequences were used for qPCR: NFKBIZ forward, 5'-CCGATTCGTTGTCTGATGGACC-3' and reverse, 5'-GCACTGCTCTCCTGTTTGGGTT-3'; and GAPDH forward, 5'-CCTTCATTGACCTCAACTACA-3' and reverse, 5'-GCTCCTGGAAGATGGTGAT-3'. The following thermocycling conditions were used for qPCR: Initial denaturation at $95^{\circ} \mathrm{C}$ for $5 \mathrm{~min}$; followed by 40 cycles at $95^{\circ} \mathrm{C}$ for $10 \mathrm{sec}$ and $60^{\circ} \mathrm{C}$ for $35 \mathrm{sec}$. The melting curve step occurred at $60-95^{\circ} \mathrm{C}$, at increments of $0.5 \mathrm{sec}$ for $5 \mathrm{sec}$. The relative expression levels of NFKBIZ were calculated using the $2^{-\Delta \Delta \mathrm{Cq}}$ method (34) and GAPDH served as the endogenous reference gene to normalize the expression levels of target mRNAs.

Western blotting. Western blotting was performed as previously described (35). Briefly, total protein was extracted from transfected T24 and 5637 cells using lysis buffer (cat. no. P0287; Beyotime Institute of Biotechnology) and the protein concentration was determined using BCA Protein assay reagent (Thermo Fisher Scientific, Inc.). Equal amounts of protein (10 $\mu \mathrm{g}$ protein/lane) were separated via $10 \%$ SDS-PAGE (Invitrogen; Thermo Fisher Scientific, Inc.) and transferred onto nitrocellulose membranes (EMD Millipore), then blocked in 5\% skimmed milk for $2 \mathrm{~h}$ at room temperature. The membranes were incubated with the following primary antibodies (all Cell Signaling Technology, Inc.) at $4^{\circ} \mathrm{C}$ overnight: Anti-NFKBIZ (1:1,000; cat. no. 9244S), anti- $\beta$-actin (1:2,000; cat. no. 4970), anti-PTEN (1:1,000; cat. no. 9188), anti-PI3K (1:1,000; cat. no. 4249), anti-p-PI3K (1:1,000; cat. no. 17366), anti-AKT (1:1,000; cat. no. 4685), anti-p-AKT (1:1,000; cat. no. 4060), anti-mTOR (1:1,000; cat. no. 2983) and anti-p-mTOR (1:1,000; cat. no. 5536). Following the primary antibody incubation, the membranes were incubated with HRP-conjugated goat anti-mouse IgG (cat. no. ab205719) and goat anti-rabbit IgG (cat. no. ab205718) (both 1:1,000; Abcam) secondary antibodies for $2 \mathrm{~h}$ at room temperature. Protein bands were visualized using the Clarity Western ECL kit
(Bio-Rad Laboratories, Inc.). $\beta$-actin was used as the internal loading control. Densitometric analysis was performed using ImageJ software (v1.8.0; National Institutes of Health).

Colony formation assay. Each group of transfected T24 and 5637 cells was digested with pancreatin, counted and plated into 6-well plates with complete medium at a density of 500 cells/well. During the 14-day incubation, the medium was changed once. Following incubation, the medium was discarded and cells were washed with PBS three times, fixed with $4 \%$ paraformaldehyde for $20 \mathrm{~min}$ at room temperature, then stained with $0.1 \%$ crystal violet solution for another $20 \mathrm{~min}$ at room temperature. Cells were subsequently washed with PBS and air-dried. The number of colonies was counted in four randomly selected fields of view using an Olympus digital camera (Olympus Corporation).

Wound healing assay. The transfected T24 and 5637 cells from each group were seeded into 6-well plates and cultured to $80-90 \%$ confluence. Scratches were subsequently made in the cell monolayer with a $200-\mu 1$ sterile pipette tip. Each well was washed 2-3 times with PBS and the plates were then cultured in serum-free medium. The width of the wound was captured at 0 and $24 \mathrm{~h}$ using a light microscope (magnification, $\mathrm{x} 200$; Nikon Corporation), and the area of cell migration $\left(\mu \mathrm{m}^{2}\right)$ was measured using ImageJ software (v1.8.0).

Transwell invasion assay. A Matrigel chamber (BD Biosciences) was used for determining the invasive ability of the cells. Briefly, the transfected T24 and 5637 cells in each group were digested and counted, and $3 \times 10^{4}$ cells/well were plated in serum-free RPMI medium into the upper chamber of 24-well Transwell plates, which had been precoated with $40 \mu \mathrm{l}$ Matrigel (BD biosciences) at $37^{\circ} \mathrm{C}$ for $1 \mathrm{~h}$. Complete medium supplemented with $10 \%$ FCS was plated into the lower chambers. Following incubation for $24 \mathrm{~h}$ at $37^{\circ} \mathrm{C}$, the cells remaining in the upper chamber were removed, while the invasive cells in the lower chamber were fixed with $4 \%$ paraformaldehyde at room temperature for $30 \mathrm{~min}$ and stained with $0.1 \%$ crystal violet solution at room temperature for 15 min (Sigma-Aldrich; Merck KGaA). The stained cells were counted in three randomly selected fields of view under a light microscope (magnification, x200; CKX41; Olympus Corporation) for each chamber.

Tumor xenograft model. A total of 6 female BALB/c nude mice (age, 4 weeks; weight, $14 \pm 2 \mathrm{~g}$ ) were obtained from the Animal Experiment Center of Wuhan University. All animals were randomly divided into two groups (n=3/group) and housed in a standard environment $\left(25^{\circ} \mathrm{C} ; 50 \%\right.$ humidity; $12-\mathrm{h}$ light/dark cycle) with free access to food and water. A volume of $200 \mu$ PBS containing $\sim 1 \times 10^{6}$ T2 4 cells transfected with pc-NC or pc-NFKBIZ were injected into the right scapular region of each mouse. The tumor volumes were measured every three days after injection and calculated using the following formula: (Length $\mathrm{x}$ width $\left.{ }^{2}\right) / 2$. After 1 month, the mice were sacrificed with $\mathrm{CO}_{2}(20 \%$ of the chamber volume was displaced per minute with $\mathrm{CO}_{2}$ ), and the tumor weight was measured immediately. The maximum tumor size observed in the present study was $1.5 \mathrm{~cm}^{3}$. The tumors were subsequently 
collected for further research. All animal protocols were approved by the Animal Care and Use Committee of Renmin Hospital of Wuhan University, and all animal experiments were conducted in accordance with the National Institutes of Health Guide for the Care and Use of Laboratory Animals.

Immunohistochemistry (IHC) assay. The paraffin-embedded tissue samples were cut into $5-\mu$ m-thick sections and the immunohistochemical expression of Ki67, NFKBIZ and PTEN in tissue sections were determined using Strept Actividin-Biotin Complex IHC staining (Wuhan Boster Biological Technology, Ltd.). The tissue sections were deparaffinized in xylene for $15 \mathrm{~min}$ at room temperature, rehydrated with a graded series of alcohol and heated at $105^{\circ} \mathrm{C}$ for $10 \mathrm{~min}$ for antigen retrieval in citric acid buffer $(0.01 \mathrm{M})$. The slides were subsequently washed with PBS for 10 min and then treated with $3 \%$ hydrogen peroxide solution to inhibit endogenous peroxidase activity, blocked with $10 \%$ normal goat serum (cat. no. AR0009; Wuhan Boster Biological Technology, Ltd.) for $30 \mathrm{~min}$ at $37^{\circ} \mathrm{C}$, and subsequently incubated with the following primary antibodies: Anti-Ki67 (1:200; cat. no. 9449; Cell Signaling Technology, Inc.), anti-NFKBIZ (1:1,000; cat. no. 9244S; Cell Signaling Technology, Inc.) and anti-PTEN (1:125; cat. no. 9188; Cell Signaling Technology, Inc.) for $2 \mathrm{~h}$ at $37^{\circ} \mathrm{C}$. The slides were washed three times with PBS and incubated with HRP-conjugated anti-mouse IgG secondary antibody (1:2,000; cat. no. sc-2005; Santa Cruz Biotechnology, Inc.) for $1 \mathrm{~h}$ at room temperature. The slides were subsequently stained using the diaminobenzidine substrate kit (cat. no. SK-4100; Vector Laboratories, Inc.). The nuclei were stained with hematoxylin for $4 \mathrm{~min}$ at room temperature, and the slides were observed under an inverted light microscope (Olympus Corporation; magnification, $\mathrm{x} 200$ ). Brown staining was considered to be Ki67-, PTEN- or NFKBIZ-positive. A total of five fields of view were randomly selected from each slide, and the degree of positive staining and the proportion of positive cells were recorded and scored by blinded observation by two pathologists. The staining intensity was classified as follows: 0 , negative; 1 , weak; 2 , moderate; and 3 , strong. The scores 0 and 1 were defined as low expression, and the scores 2 and 3 were defined as high expression.

Statistical analysis. Statistical analysis was performed using GraphPad Prism 5 (GraphPad Software, Inc.) and SPSS 12.0 (SPSS, Inc.) softwares, and quantitative data are presented as the mean \pm SD. The RT-qPCR data of tumor and non-tumor tissues from patients were compared using paired t-test. An independent-sample t-test was used to analyze the differences between two groups. One-way ANOVA with Tukey's post-hoc test was used to analyze the statistical differences among multiple groups. Categorical data were compared using Fisher's exact test. Correlation analysis was preformed using Spearman correlation coefficient algorithm. All experiments were independently repeated in triplicate. $\mathrm{P}<0.05$ was considered to indicate a statistically significant difference.

\section{Results}

NFKBIZ expression is downregulated in human BC tissues and is associated with a poor prognosis. As shown in Table I,
NFKBIZ expression in clinical patients with $\mathrm{BC}$ was associated with tumor stage $(\mathrm{P}=0.005)$ and tumor grade $(\mathrm{P}=0.018)$. However, no associations were observed between NFKBIZ expression and other clinical features, such as sex $(\mathrm{P}=0.306)$, age $(\mathrm{P}=0.154)$, tumor size $(\mathrm{P}=0.672)$ and tumor multiplicity $(\mathrm{P}>0.999)$. The bioinformatics analysis revealed that NFKBIZ mRNA expression was significantly downregulated in cancer tissues compared with in normal tissues (Fig. 1A-C), and at different stages, nodal metastasis status and histological subtypes compared with normal tissues, which suggests that the low NFKBIZ expression may be associated with a poor prognosis in patients with BC (Fig. 1D-F). To further validate the results obtained from databases, the expression levels of NFKBIZ in clinical BC tissues and cell lines were analyzed using RT-qPCR and western blotting, respectively. The results revealed that the expression levels of NFKBIZ in $\mathrm{BC}$ tissues and cell lines were significantly downregulated compared with in adjacent non-tumor tissues and normal bladder epithelial cells, respectively (Fig. 1G-I). Additionally, survival analysis indicated that patients with $\mathrm{BC}$ with high NFKBIZ expression had an increased overall survival rate compared with those with low NFKBIZ expression (Fig. 1J). The current results suggested that NFKBIZ may be act as a tumor suppressor gene and may serve an important role in BC progression.

NFKBIZ suppresses cell proliferation, migration and invasion. To investigate the biological role of NFKBIZ in BC progression, T24 and 5637 cells were selected as in vitro cell models, since NFKBIZ expression was the lowest in these cell lines. The two cell lines were infected with lentivirus particles against puromycin to induce the stable overexpression of NFKBIZ, and the cell proliferative, migratory and invasive abilities were determined. Fluorescence microscopy, RT-qPCR and western blot analyses confirmed the transfection efficiency in the two cell lines (Fig. 2A-D). According to the results of the colony formation assay, the number of colonies formed from T24 (Fig. 2E and F) and 5637 (Fig. 2G and H) cells in the pc-NFKBIZ group was significantly decreased compared with in the pc-NC group. The results of the wound healing assay demonstrated that compared with in the pc-NC group, the migration rate of T24 (Fig. 2I and J) and 5637 (Fig. 2K and L) cells was significantly inhibited in the pc-NFKBIZ group. Moreover, the Transwell invasion assay results revealed that there were significantly fewer invasive T24 (Fig. 2M and N) and 5637 (Fig. $2 \mathrm{O}$ and P) cells in the pc-NFKBIZ group compared with in the pc-NC group. These results suggested that $\mathrm{BC}$ cell proliferation, migration and invasion were suppressed following the overexpression of NFKBIZ.

NFKBIZ expression affects $B C$ growth in vivo. To determine the effects of NFKBIZ expression on BC growth in vivo, T24 cells were used to establish a xenograft model. The tumor weights and volumes were significantly decreased in the pc-NFKBIZ group compared with in the pc-NC group (Fig. 3A-C). In addition, the IHC results demonstrated that $\mathrm{Ki}-67$ expression (a proliferation marker) was markedly decreased in the pc-NFKBIZ group compared with in the pc-NC group (Fig. 3D). These results indicated that $\mathrm{BC}$ growth was inhibited by the overexpression of NFKBIZ in vivo. 
Table I. Association between NFKBIZ expression and clinical features of patients with bladder cancer $(n=34)$.

\begin{tabular}{|c|c|c|c|c|}
\hline Variable & Total & Low NFKBIZ expression $(n=28)$ & High NFKBIZ expression $(n=6)$ & P-value \\
\hline \multicolumn{5}{|l|}{ Sex } \\
\hline Male & 25 & 22 & 3 & \multirow[t]{2}{*}{0.306} \\
\hline Female & 9 & 6 & 3 & \\
\hline \multicolumn{5}{|l|}{ Age, years } \\
\hline$\geq 60$ & 22 & 20 & 2 & \multirow[t]{2}{*}{0.154} \\
\hline$<60$ & 12 & 8 & 4 & \\
\hline \multicolumn{5}{|l|}{ Tumor size, $\mathrm{cm}$} \\
\hline$\geq 3$ & 20 & 17 & 3 & \multirow[t]{2}{*}{0.672} \\
\hline$<3$ & 14 & 11 & 3 & \\
\hline \multicolumn{5}{|l|}{ Multiplicity of tumor } \\
\hline Single & 17 & 14 & 3 & \multirow[t]{2}{*}{$>0.999$} \\
\hline Multiple & 17 & 14 & 3 & \\
\hline \multicolumn{5}{|l|}{ Tumor grade } \\
\hline PUNLMP, low grade & 8 & 4 & 4 & \multirow[t]{2}{*}{0.018} \\
\hline High grade & 26 & 24 & 2 & \\
\hline \multicolumn{5}{|l|}{ Tumor stage } \\
\hline Ta, T1 & 10 & 5 & 5 & \multirow[t]{2}{*}{0.005} \\
\hline $\mathrm{T} 2-\mathrm{T} 4$ & 24 & 23 & 1 & \\
\hline \multicolumn{5}{|l|}{ Lymph node status } \\
\hline Negative & 26 & 22 & 4 & \multirow[t]{2}{*}{0.609} \\
\hline Positive & 8 & 6 & 2 & \\
\hline \multicolumn{5}{|l|}{ Distant metastasis } \\
\hline Absent & 34 & 28 & 6 & \\
\hline Present & 0 & 0 & 0 & \\
\hline
\end{tabular}

NFKBIZ, NF- $\mathrm{KB}$ inhibitor $\xi$; PUNLMP, papillary urothelial neoplasms of low malignant potential.

NFKBIZ and PTEN expression levels are positively correlated. To investigate the potential mechanism of the aforementioned biological functions of NFKBIZ in vivo and in vitro, correlation analysis was performed. The results identified a positive correlation between NFKBIZ and the tumor-inhibiting factor, PTEN (Fig. 4A). To determine whether the overexpression of NFKBIZ induced the expression levels of PTEN, its expression was analyzed in both T24 and 5637 cells using western blotting (Fig. 4B and C). Moreover, according to the RT-qPCR results of clinical $\mathrm{BC}$ tissues, samples in the NFKBIZ high expression and low expression groups were selected to conduct PTEN or NFKBIZ IHC, and to investigate whether PTEN expression was also high in the NFKBIZ high expression group or low in the NFKBIZ low expression group, to further explore whether NFKBIZ expression was positively correlated with PTEN expression. The IHC results from human BC and nude mice tumor tissues revealed that the overexpression of NFKBIZ upregulated PTEN expression (Fig. 4D and E). These results suggested the existence of a positive correlation between the expression levels of NFKBIZ and PTEN.

PTEN inhibition promotes BC cell proliferation, migration and invasion. To further verify the positive correlation between NFKBIZ and PTEN, NFKBIZ-overexpressing T24 and 5637 cells were treated with the PTEN inhibitor VO $(35 \mathrm{nM} / \mathrm{l})$ at room temperature for $24 \mathrm{~h}$, to observe the effect on cell proliferation, migration and invasion. According to the results of the colony formation assay, the number of colonies formed from T24 (Fig. 5A and C) and 5637 (Fig. 5B and D) cells in the pc-NFKBIZ + VO group was significantly increased compared with in the pc-NFKBIZ group. The wound healing assay results demonstrated that, compared with in the pc-NFKBIZ group, the migratory rate of T24 (Fig. 5E and F) and 5637 (Fig. 5G and $\mathrm{H}$ ) cells was significantly increased in the pc-NFKBIZ + VO group. In addition, the results of the Transwell invasion assay revealed that the number of invasive T24 (Fig. 5I and K) and 5637 (Fig. 5J and L) cells was significantly increased in the pc-NFKBIZ + VO group compared with in the pc-NFKBIZ group.

According to the aforementioned results, treatment with VO enhanced the proliferative, migratory and invasive abilities induced by NFKBIZ overexpression in T24 and 5637 cells. Thus, the findings suggested that NFKBIZ may function as an important tumor suppressor and may positively modulate the tumor-inhibiting factor, PTEN, in BC.

NFKBIZ suppresses $B C$ by regulating the PTEN/PI3K/AKT signaling pathway in $B C$ cells. The PI3K/AKT/mTOR 

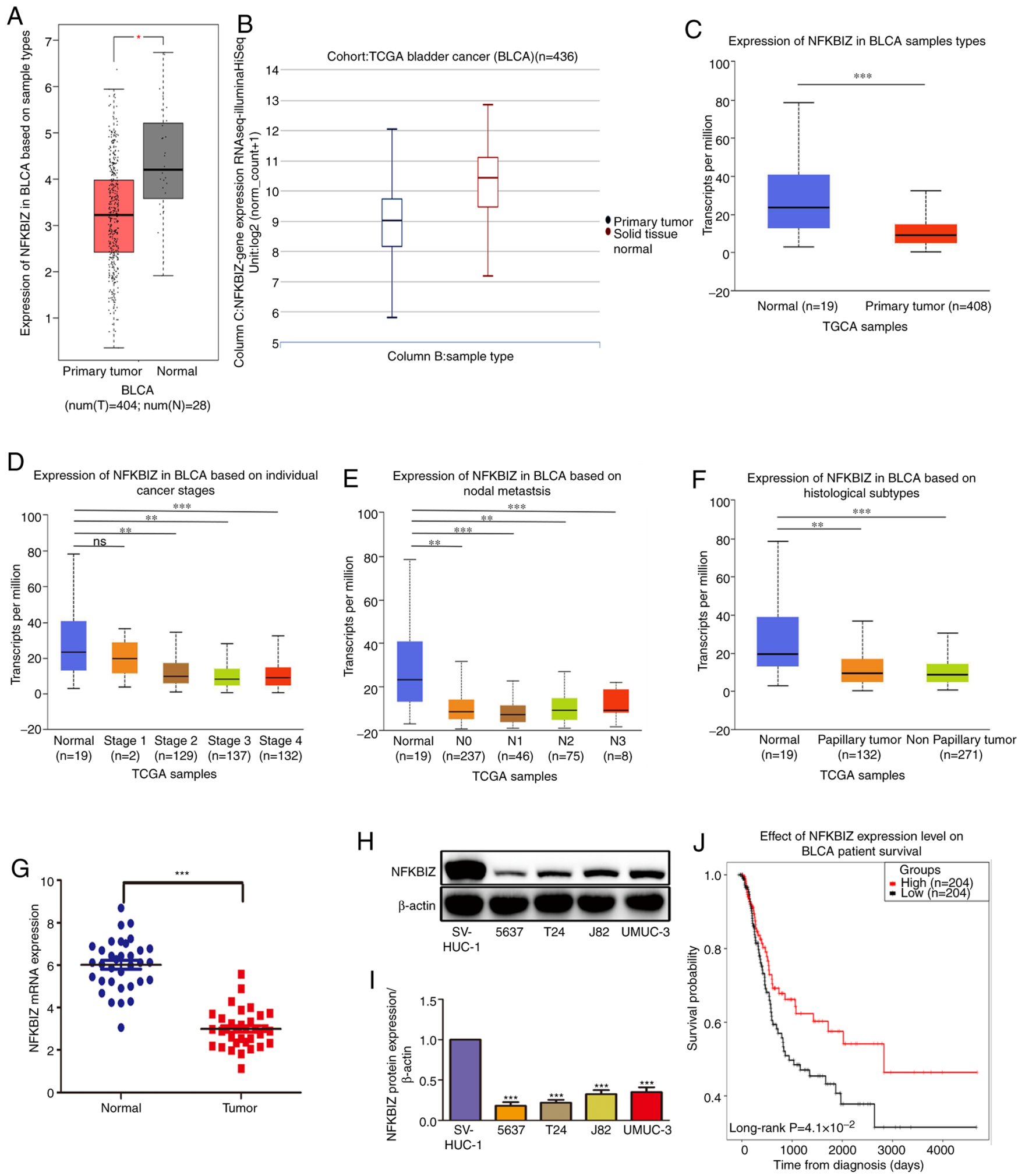

Figure 1. NFKBIZ expression is significantly downregulated in BC, and its low expression predicts a poor prognosis. (A) NFKBIZ expression in BLCA based on sample types in the Gene Expression Profiling Interacting Analysis database. (B) Expression levels of NFKBIZ based on RNAseq data in BLCA based on sample types in the Xena database. NFKBIZ expression according to (C) sample types, (D) different BC stages, (E) nodal metastasis status and (F) histological subtypes in the UALCAN database. (G) Reverse transcription-quantitative PCR analysis of NFKBIZ expression in 34 pairs of BC tissues and corresponding adjacent normal bladder tissues. ${ }^{*} \mathrm{P}<0.05 ;{ }^{* *} \mathrm{P}<0.01 ;{ }^{* * *} \mathrm{P}<0.001$. (H) Representative western blot images and (I) quantitative analyses of NFKBIZ and $\beta$-actin protein expression in different cell lines. ${ }^{* * *} \mathrm{P}<0.001$ vs. SV-HUC-1. (J) Survival analysis was performed using the mRNA-reads count expression data from TCGA-BLCA dataset in patients with BC with high and low NFKBIZ expression. ns, not significant; BLCA/BC, bladder cancer; TCGA, The Cancer Genome Atlas; RNAseq, RNA sequencing; NFKBIZ, NF-kB inhibitor $\zeta$.

signaling pathway serves an important role in numerous types of cancer and regulates a wide range of cellular processes, including survival, proliferation, growth, metabolism, angiogenesis and metastasis (36). Thus, the present 


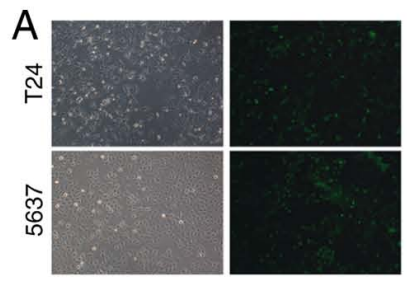

E

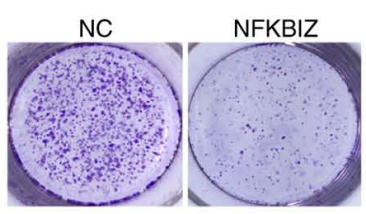

T24
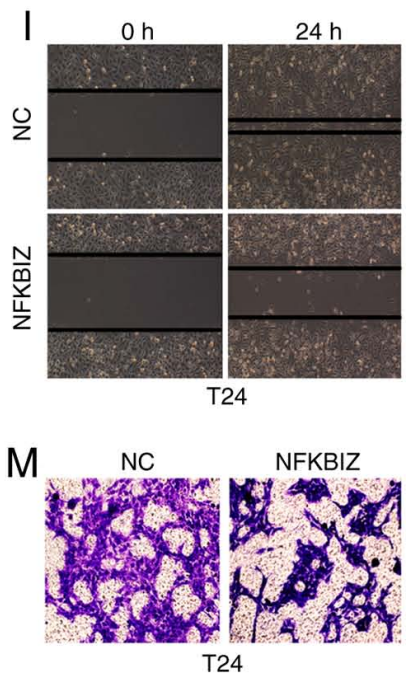
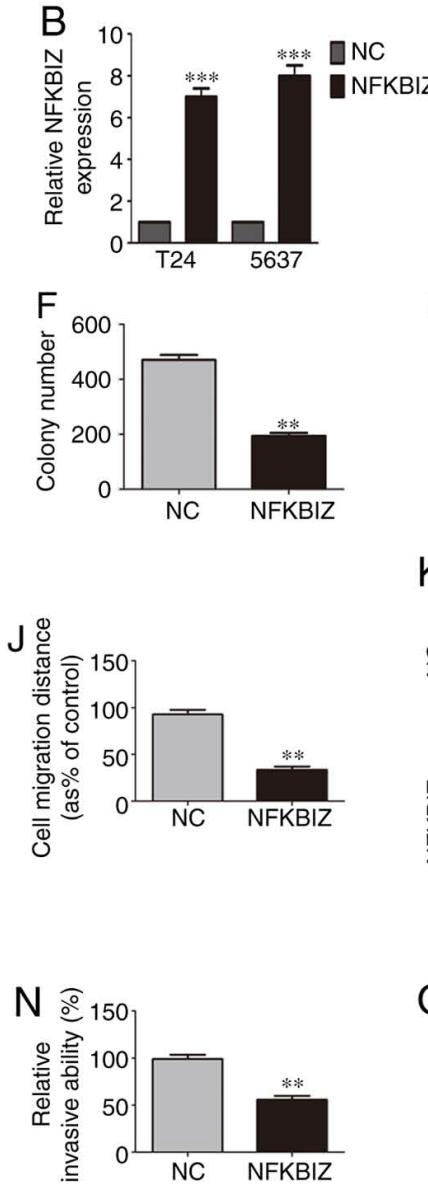
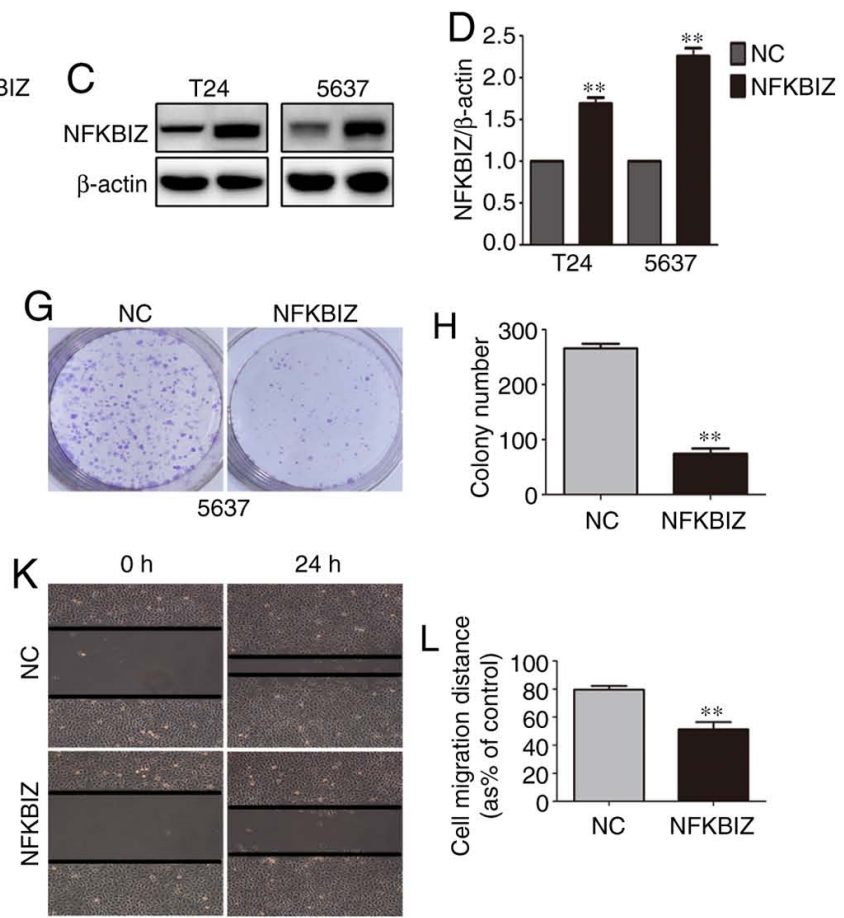

5637

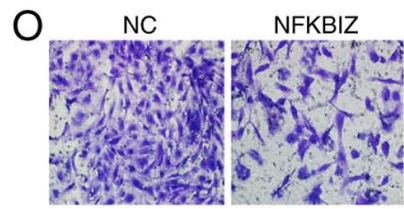

5637

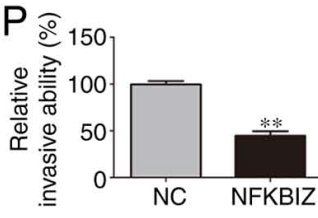

Figure 2. Overexpression of NFKBIZ affects bladder cancer cell proliferation, migration and invasion in vitro. (A) Representative images of transfected T24 and 5637 cells were captured using a fluorescence microscope (magnification, x200). NFKBIZ transfection efficiency was evaluated by (B) Reverse transcription-quantitative PCR and (C and D) western blotting in T24 and 5637 cell lines. Representative images and quantitative analyses of (E and F) T24 and (G and H) 5637 cell colonies in each group according to colony formation assays. Representative images and quantitative analyses of (I and J) T24 and (K and L) 5637 cell migration rates in each group according to wound healing assays (magnification, x200). Representative images and quantitative analyses of invasive (M and N) T24 and (O and P) 5637 cells in each group according to Transwell invasion assays (magnification, $\mathrm{x} 200$ ). ${ }^{* * *} \mathrm{P}<0.01$ and ${ }^{* * * *} \mathrm{P}<001 \mathrm{vs}$. NC. NC, negative control; NFKBIZ, NF- $\mathrm{B}$ inhibitor $\zeta$.
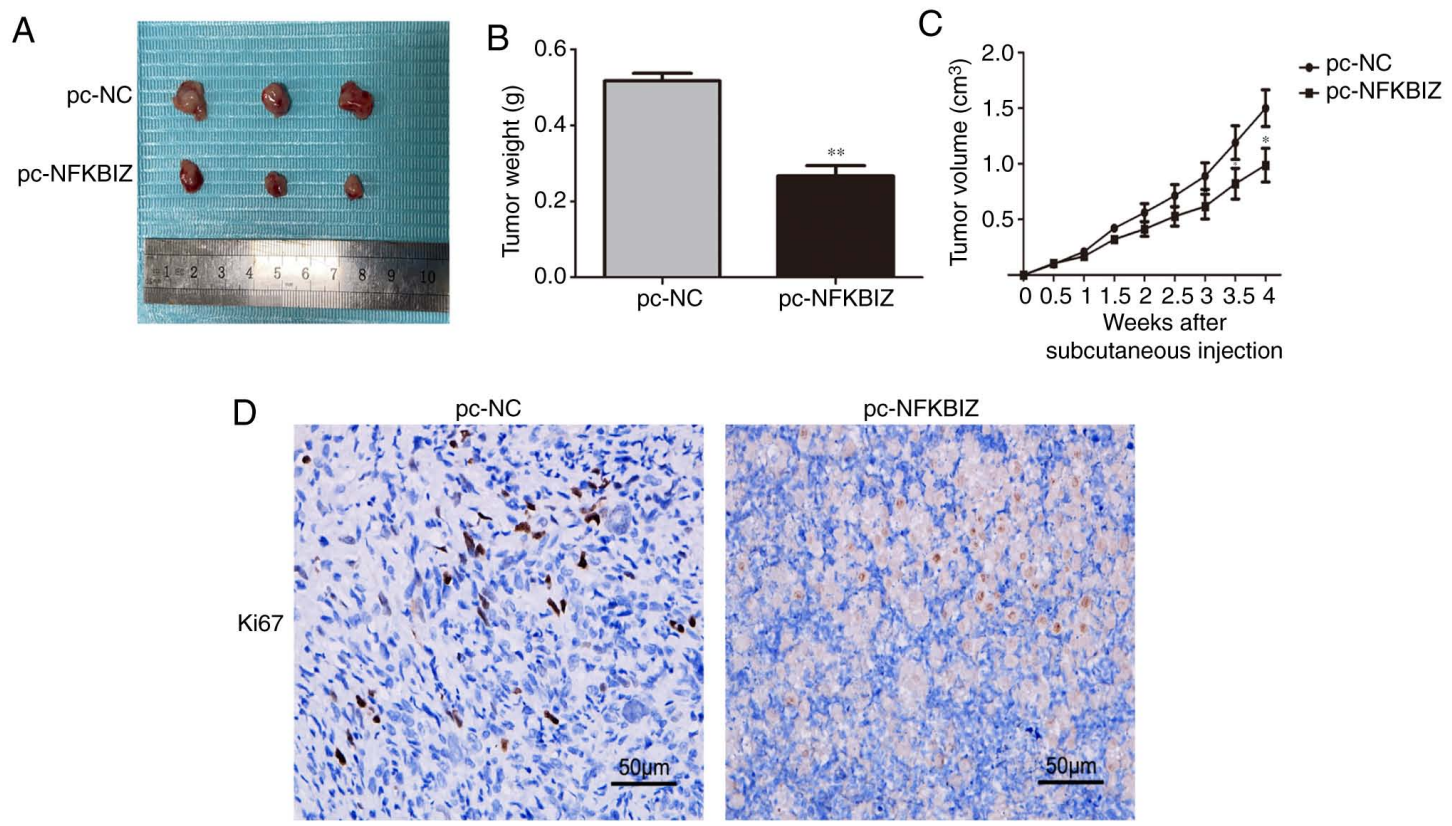

Figure 3. Overexpression of NFKBIZ affects bladder cancer growth in vivo. (A) Representative images of the isolated tumors from mice ( $\mathrm{n}=3$ /group), as well as the (B) weight and (C) volume of the tumors from T24 cells in the pc-NC and pc-NFKBIZ groups. (D) Representative immunohistochemistry images of Ki-67 expression in the mice tumors from T2 4 cells (magnification, $\mathrm{x} 200$; scale bar, $50 \mu \mathrm{m}$ ). ${ }^{*} \mathrm{P}<0.05$ and ${ }^{* *} \mathrm{P}<0.01$ vs. pc-NC. NC, negative control; NFKBIZ, NF- $\kappa \mathrm{B}$ inhibitor $\zeta$. 

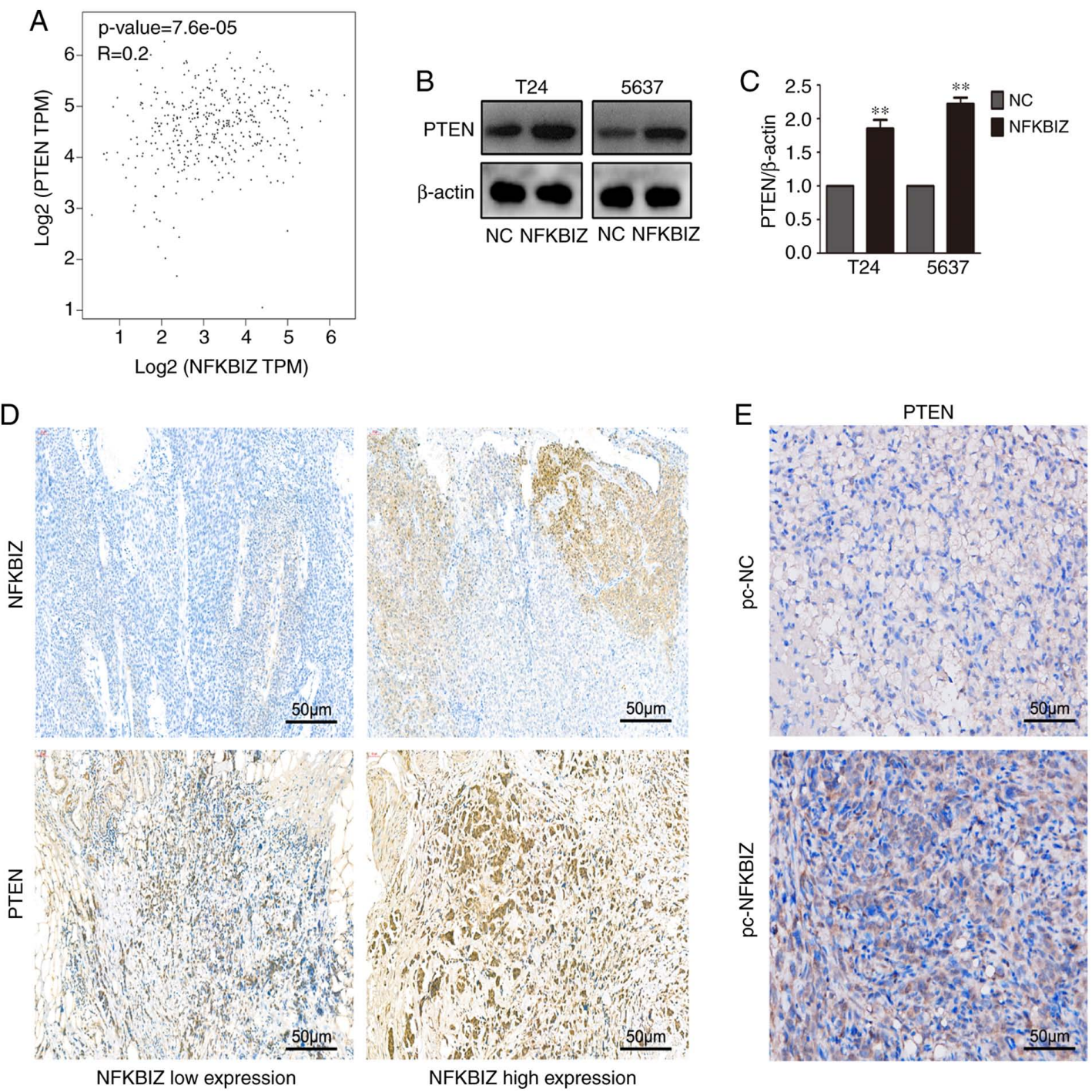

Figure 4. Expression levels of NFKBIZ and PTEN are positively correlated. (A) NFKBIZ expression was significantly positively correlated with PTEN expression according to the Gene Expression Profiling Interacting Analysis database. (B and C) PTEN expression was increased in transfected T24 and 5637 cells overexpressing NFKBIZ. (D) Representative IHC images of NFKBIZ and PTEN expression in human bladder cancer tissues (magnification, x200; scale bar, $50 \mu \mathrm{m}$ ). (E) Representative IHC images of PTEN expression in nude mice tumor tissues in the pc-NFKBIZ and pc-NC groups. ${ }^{* *} \mathrm{P}<0.01 \mathrm{vs}$. NC. NC, negative control; NFKBIZ, NF- $\mathrm{kB}$ inhibitor $\zeta$; IHC, immunohistochemistry; TPM, transcripts per million.

study determined the effect of NFKBIZ overexpression on the signaling activity of this pathway. The results revealed a significant downregulation in the levels of key molecules involved in the AKT signaling pathway, including p-PI3K, p-AKT and p-mTOR, in T24 and 5637 cells overexpressing NFKBIZ; however, the expression levels of the total proteins were unchanged (Fig. 6A-D). PTEN is directly upstream of the AKT signaling pathway (23). To further determine whether the activation of the PTEN/AKT/mTOR signaling pathway was important for the oncogenic activity of NFKBIZ in BC cells, NFKBIZ-overexpressing T24 and 5637 cells were treated with VO. The treatment of T24 and 5637 cells overexpressing NFKBIZ with VO rescued the inhibition of AKT signaling activity induced by the overexpression of NFKBIZ (Fig. 6E-G). These findings suggested that the overexpression of NFKBIZ may suppress BC cell proliferation, migration and invasion by inducing PTEN expression, and the mechanism may depend on PTEN/PI3K/AKT/mTOR signaling.

\section{Discussion}

$\mathrm{BC}$ is one of the most common and invasive malignant tumors; however, the treatment of the disease is challenging. Although some progress has been made in the early diagnosis and comprehensive treatment of $\mathrm{BC}$, the prognosis remains unsatisfactory (37). Therefore, there is an urgent requirement to elucidate the molecular mechanisms of the $\mathrm{BC}$ regulatory network.

NFKBIZ, an inhibitor of the I $\mathrm{B}$ protein, is localized to the nucleus (12). Several previous studies have reported that NFKBIZ serves a potentially important role in modulating the progression of numerous inflammatory diseases, such as spontaneous skin inflammation, invasive pneumococcal disease and Crohn's disease $(19,20,38,39)$. Notably, inflammation is also known to serve an important role in the development of cancer (40). However, the underlying pathological mechanisms of NFKBIZ in cancer remain elusive. Therefore, the present study aimed to determine the role of NFKBIZ in BC. 
A
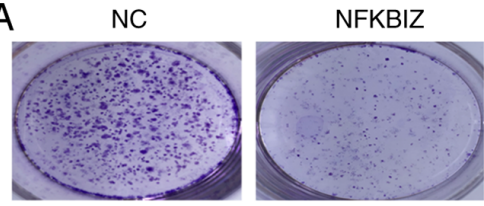

T24

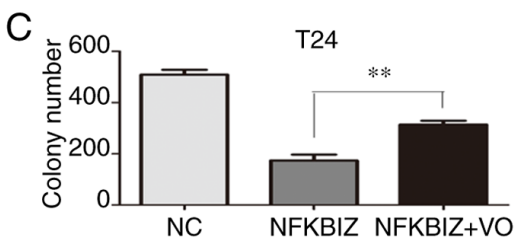

B
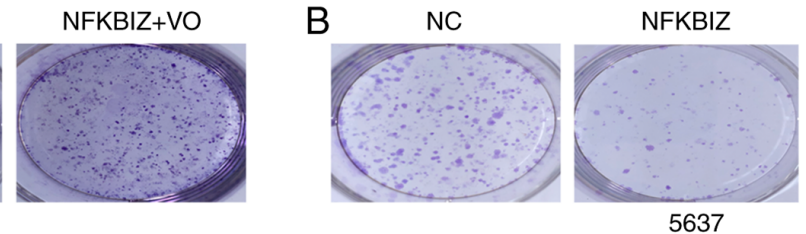

D

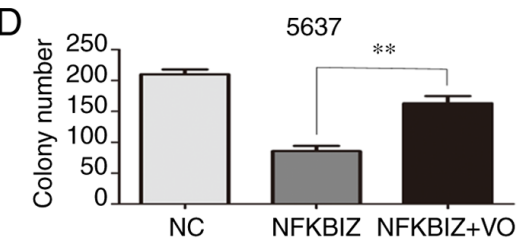

$\mathrm{NFKBIZ+VO}$

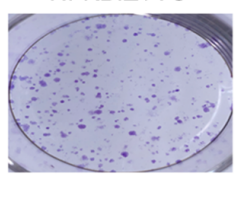

\section{.}

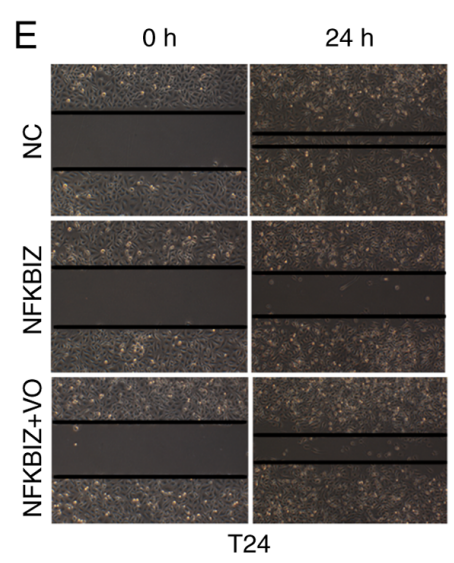

$F \stackrel{8}{\complement}$

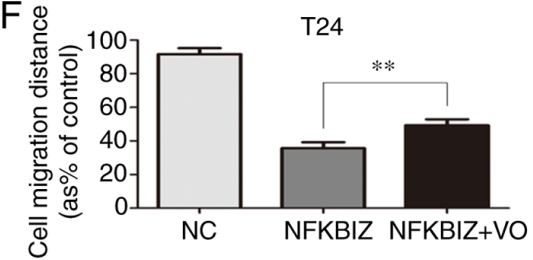

$\mathrm{H} \stackrel{8}{\mathscr{0}}$

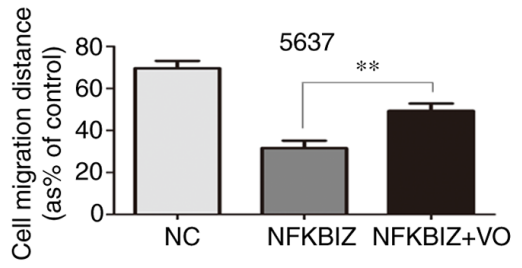

G

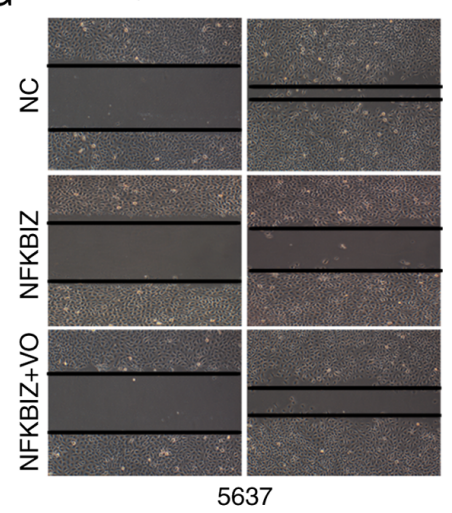

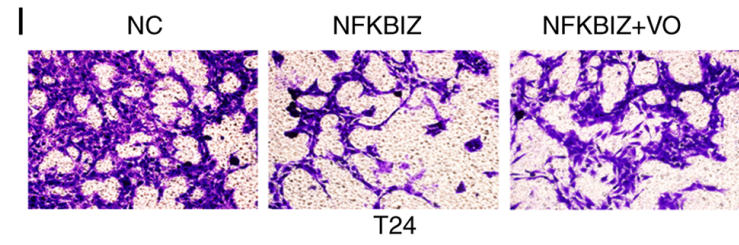

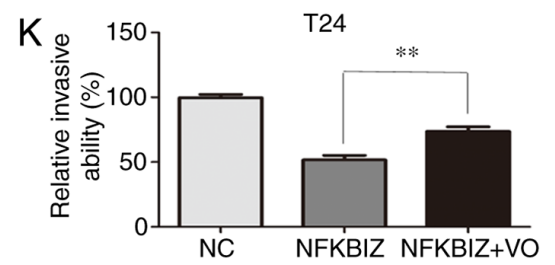

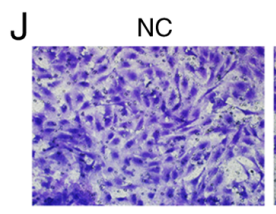

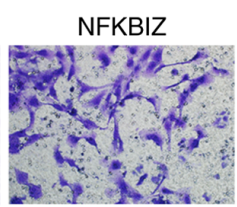

$\mathrm{NFKBIZ+VO}$

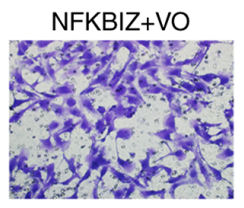

5637

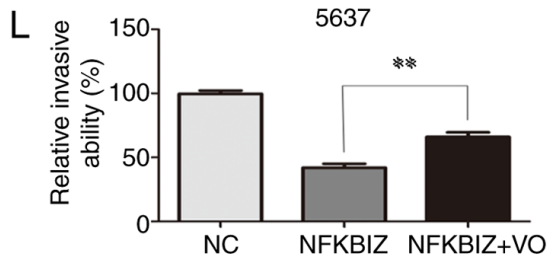

Figure 5. Treatment with the PTEN inhibitor VO enhanced the proliferation, migration and invasion in T24 and 5637 cells overexpressing NFKBIZ. (A and B) Representative images and (C and D) quantitative analyses of T24 and 5637 cell colonies in each group according to colony formation assays. Representative images and quantitative analyses of ( $\mathrm{E}$ and F) T24 and (G and H) 5637 cell migration rates in each group according to wound healing assays (magnification, x200). (I and J) Representative images and ( $\mathrm{K}$ and L) quantitative analyses of invasive T24 and 5637 cells in each group according to Transwell invasion assays (magnification, $\mathrm{x} 200$ ). ${ }^{* *} \mathrm{P}<0.01$. VO, VO-OHpic trihydrate; NC, negative control; NFKBIZ, NF- $\kappa \mathrm{B}$ inhibitor $\zeta$.

PTEN is a widely studied tumor suppressor gene involved in the majority of human malignant tumors (25). PTEN signaling has been found to inhibit the occurrence and development of cancer by inhibiting the proliferation, migration and invasion of cancer cells (25). Therefore, the activation of the PTEN signaling pathway has been considered to be a promising therapeutic strategy for the clinical treatment of cancer (41). In a previous study, the inactivation of the PTEN signaling pathway has been associated with the invasiveness of BC (42). PTEN, as an inhibitor of the PI3K/AKT signaling pathway, inhibits the growth and invasion of tumor cells by directly inhibiting the PI3K/AKT signaling pathway (43). In addition, the $\mathrm{PI} 3 \mathrm{~K} / \mathrm{AKT} / \mathrm{mTOR}$ signaling pathway is a classical signaling pathway that has a crucial role in regulating cell growth, metastasis and other cellular processes in various types of cancer, including BC (44-47). Previous studies have shown that the PI3K/AKT/mTOR signaling pathway is activated in $\mathrm{BC}$, and patients with $\mathrm{BC}$ with simultaneous expression of $\mathrm{PI} 3 \mathrm{~K} / \mathrm{AKT} / \mathrm{mTOR}$ exhibit a worse prognosis $(48,49)$. NF- $\mathrm{KB}$ correlates with PTEN (29-31) and is controlled by NFKBIZ (12). To determine the molecular mechanisms of NFKBIZ regulation over BC cell proliferation, invasion and migration, the present study analyzed the expression levels of proteins involved in the PTEN/PI3K/AKT/mTOR signaling pathway. 

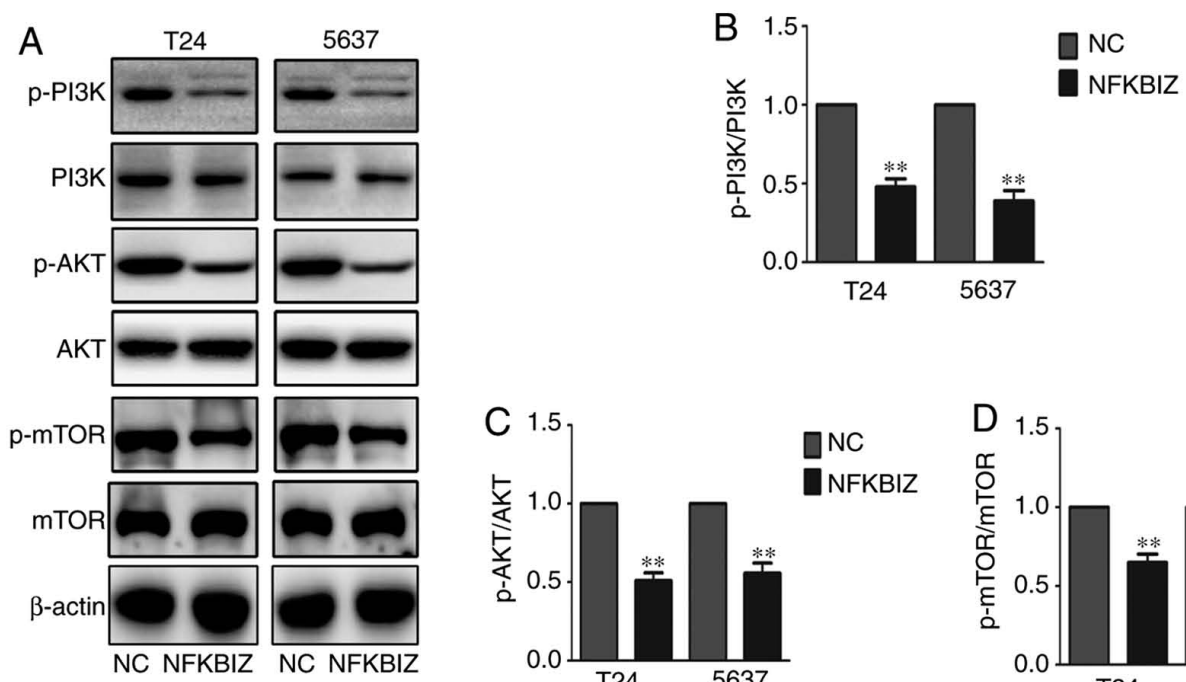

$\mathrm{E}$

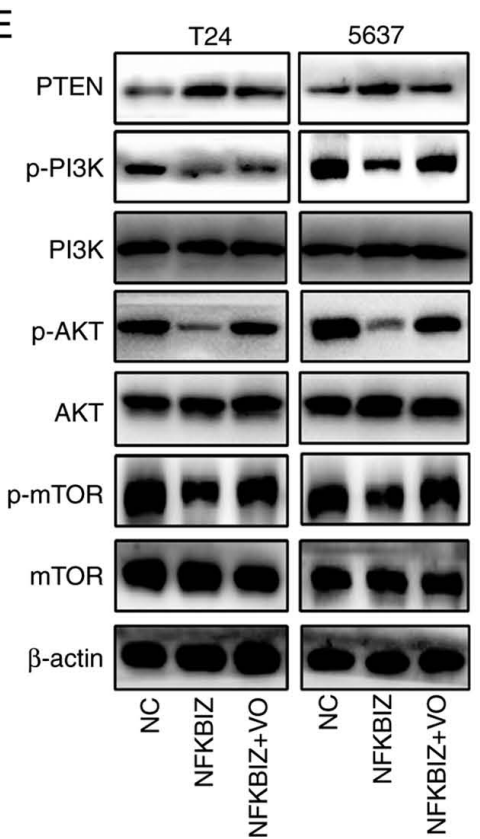

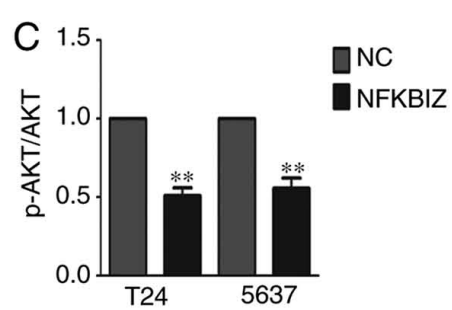

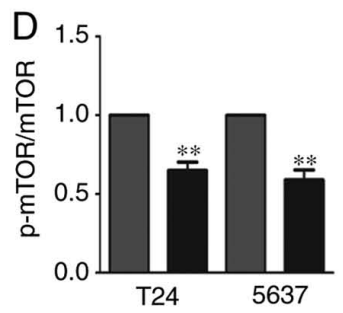

T24
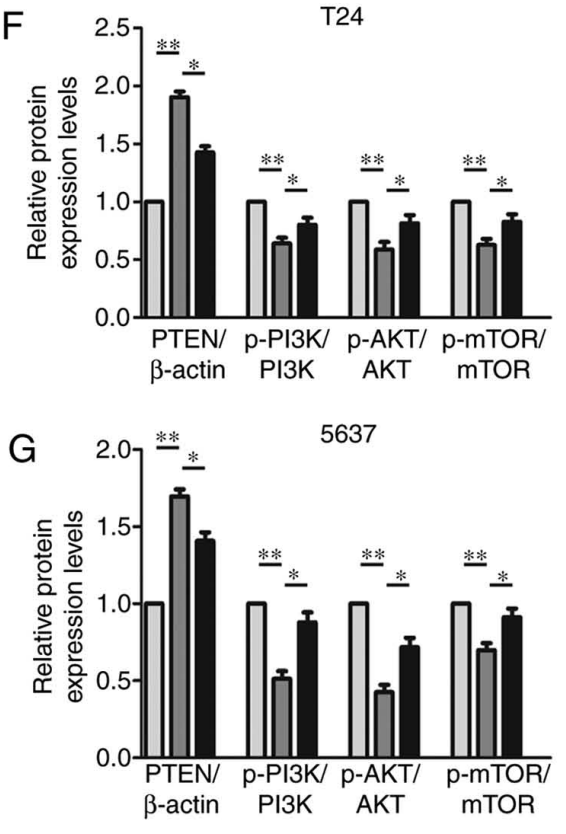

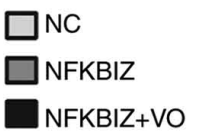

$\square \mathrm{NC}$ WFKBIZ

Figure 6. Overexpression of NFKBIZ induces BC cell proliferation by regulating the PTEN/PI3K/Akt signaling pathway in BC cells. (A) Representative western blot images and quantitative analyses of related proteins, including (B) p-PI3K/PI3K, (C) p-AKT/AKT and (D) p-mTOR/mTOR in transfected T24 and 5637 cells overexpressing NFKBIZ. ${ }^{* *} \mathrm{P}<0.01$ vs. NC. (E) Representative western blot images and quantitative analyses of related proteins, including PTEN, p-PI3K/PI3K, p-AKT/AKT and p-mTOR/mTOR in transfected (F) T24 and (G) 5637 cells overexpressing NFKBIZ and after VO treatment. ${ }^{*} \mathrm{P}<0.05 ;{ }^{* * *} \mathrm{P}<0.01$. VO, VO-OHpic trihydrate; NC, negative control; NFKBIZ, NF- $\kappa$ B inhibitor $\zeta$; p, phosphorylated; BC, bladder cancer.

In the present study, the expression levels of NFKBIZ were significantly downregulated in $\mathrm{BC}$ samples and cell lines, and positively associated with the overall survival rate of patients. In addition, NFKBIZ expression at different stages, nodal metastasis status and histological subtypes was significantly decreased compared with in normal tissues, which suggested that low NFKBIZ expression may be associated with a poor prognosis in patients with BC. However, in 34 clinical samples, there was no association between lymph node metastasis and NFKBIZ expression, which was in contrast to the results obtained from the database analysis and may be due to the limited number of clinical specimens available for analysis. To verify whether NFKBIZ acted as a tumor suppressor, lentiviruses overexpressing NFKBIZ were transfected into BC cell lines to verify the results of the bioinformatics analysis. Mechanistically,
NFKBIZ suppressed BC cell proliferation, migration and invasion. In addition, the data from the tumor xenograft model studies revealed that $\mathrm{BC}$ growth was inhibited by the overexpression of NFKBIZ, which provided further evidence for the suggested tumor-suppressive role of NFKBIZ in BC. Ki67 has been considered as a useful biomarker for $\mathrm{BC}$, and its expression has been associated with a poor prognosis (50). In the current study, the upregulated expression levels of NFKBIZ were associated with the downregulated expression levels of Ki67, which is suggestive of an improved prognosis. Therefore, it may be inferred that the expression levels of NFKBIZ may be downregulated as the stage of the disease advances. Subsequently, the present study aimed to determine which pathway affected the progression of $\mathrm{BC}$. The results of the current study revealed that PTEN expression was positively correlated with NFKBIZ 
expression, which was proven using the GEPIA database and IHC results obtained from clinical specimens. In addition, further results revealed that NFKBIZ affected BC cells by upregulating PTEN expression, which was followed by the inactivation of the PI3K/AKT/mTOR signaling pathway. These effects were reversed by the PTEN inhibitor VO. The current results suggested that the regulation of NFKBIZ expression may be a novel target in the treatment of $\mathrm{BC}$.

In the present study, VO downregulated PTEN expression and indirectly activated the PI3K/Akt/mTOR signaling pathway, and then reversed the anticancer effects of NFKBIZ overexpression, which is consistent with previous studies (51-53). Additionally, another study has revealed that high concentration of VO can inhibit hepatocarcinoma cell proliferation and induce senescence (54). Whether high concentration of $\mathrm{VO}$ can directly inhibit $\mathrm{BC}$ cell proliferation should be further explored in future studies.

In conclusion, to the best of our knowledge, the findings of the present study revealed for the first time that NFKBIZ may serve as a tumor suppressor to inhibit tumor growth both in vitro and in vivo. In addition, NFKBIZ expression was positively correlated with PTEN expression, which affected BC tumorigenesis through the PTEN-mediated inhibition of the $\mathrm{PI} 3 \mathrm{~K} / \mathrm{AK}$ T/mTOR signaling pathway. Furthermore, the results demonstrated that upregulated expression levels of NFKBIZ were an indicator of an improved prognosis in patients with $\mathrm{BC}$. Therefore, the data of the present study revealed the molecular mechanism of the NFKBIZ-mediated regulation of $\mathrm{BC}$, and the NFKBIZ/PTEN/PI3K/AKT axis may represent a novel clinical marker and therapeutic target for $\mathrm{BC}$.

\section{Acknowledgements}

Not applicable.

\section{Funding}

The present study was supported by grants from the National Natural Science Foundation of China (grant. nos. 81870471 and 81800617) and the Science and Technology Major Project of Hubei Province (grant. no. 2019AEA170).

\section{Availability of data and materials}

All data generated or analyzed during this study are included in this published article.

\section{Authors' contributions}

TX designed the study. TX, WMY, JZN and XY performed the experiments and drafted the manuscript. SMZ, KY and TB participated in data analysis. TX, TR and FC were involved in the discussion and interpretation of the results. TX and FC were responsible for confirming the authenticity of the data. All authors have read and approved the final manuscript.

\section{Ethics approval and consent to participate}

All patients provided written informed consent and the research protocols were approved by the Research Ethics
Committee of Renmin Hospital of Wuhan University (approval no. WDRY2019-K035; Wuhan, China). All animal protocols were approved by the Animal Care and Use Committee of Renmin Hospital of Wuhan University, and all animal experiments were conducted in accordance with the National Institutes of Health Guide for the Care and Use of Laboratory Animals.

\section{Patient consent for publication}

Not applicable.

\section{Competing interests}

The authors declare that they have no competing interests.

\section{References}

1. Siegel RL, Miller KD and Jemal A: Cancer statistics, 2018. CA Cancer J Clin 68: 7-30, 2018.

2. Antoni S, Ferlay J, Soerjomataram I, Znaor A, Jemal A and Bray F: Bladder cancer incidence and mortality: A global overview and recent trends. Eur Urol 71: 96-108, 2017.

3. Song BN, Kim SK, Mun JY, Choi YD, Leem SH and Chu IS Identification of an immunotherapy-responsive molecular subtype of bladder cancer. EBioMedicine 50: 238-245, 2019.

4. Chou R, Selph SS, Buckley DI, Gustafson KS, Griffin JC, Grusing SE and Gore JL: Treatment of muscle-invasive bladder cancer: A systematic review. Cancer 122: 842-851, 2016.

5. Jemal A, Siegel R, Ward E, Murray T, Xu J and Thun MJ: Cancer statistics, 2007. CA Cancer J Clin 57: 43-66, 2007.

6. Levi F, La Vecchia C, Randimbison L and Franceschi S: Incidence of infiltrating cancer following superficial bladder carcinoma. Int J Cancer 55: 419-421, 1993.

7. Witjes JA, Compérat E, Cowan NC, De Santis M, Gakis G, Lebret T, Ribal MJ, Van der Heijden AG and Sherif A; European Association of Urology: EAU guidelines on muscle-invasive and metastatic bladder cancer: Summary of the 2013 guidelines. Eur Urol 65: 778-792, 2014

8. Zhu G, Xu Y, Cen X, Nandakumar KS, Liu S and Cheng K: Targeting pattern-recognition receptors to discover new small molecule immune modulators. Eur J Med Chem 144: 82-92, 2018

9. Herrero-Beaumont G, Pérez-Baos S, Sánchez-Pernaute $O$, Roman-Blas JA, Lamuedra A and Largo R: Targeting chronic innate inflammatory pathways, the main road to prevention of osteoarthritis progression. Biochem Pharmacol 165: 24-32, 2019.

10. Napetschnig $\mathbf{J}$ and $\mathrm{Wu} \mathrm{H}$ : Molecular basis of $\mathrm{NF}-\kappa \mathrm{B}$ signaling. Annu Rev Biophys 42: 443-468, 2013.

11. Baldwin AS Jr: The NF-kappa B and I kappa B proteins: New discoveries and insights. Annu Rev Immunol 14: 649-683, 1996.

12. Willems M, Dubois N, Musumeci L, Bours V and Robe PA: IкB An emerging player in cancer. Oncotarget 7: 66310-66322, 2016.

13. Horber S, Hildebrand DG, Lieb WS, Lorscheid S, Hailfinger S, Schulze-Osthoff $\mathrm{K}$ and Essmann F: The Atypical Inhibitor of $\mathrm{NF}-\kappa \mathrm{B}, \mathrm{I} \kappa \mathrm{B} \zeta$, controls macrophage interleukin-10 expression. J Biol Chem 291: 12851-12861, 2016.

14. Wu Z, Zhang X, Yang J, Wu G, Zhang Y, Yuan Y, Jin C, Chang Z, Wang J, Yang X and He F: Nuclear protein IkappaB-zeta inhibits the activity of STAT3. Biochem Biophys Res Commun 387: 348-352, 2009.

15. Nogai H, Wenzel SS, Hailfinger S, Grau M, Kaergel E, Seitz V, Wollert-Wulf B, Pfeifer M, Wolf A, Frick M, et al: IкB- $\zeta$ controls the constitutive NF- $\kappa$ B target gene network and survival of $A B C$ DLBCL. Blood 122: 2242-2250, 2013.

16. Yamamoto M, Yamazaki S, Uematsu S, Sato S, Hemmi H, Hoshino K, Kaisho T, Kuwata H, Takeuchi O, Takeshige K, et al: Regulation of Toll/IL-1-receptor-mediated gene expression by the inducible nuclear protein IkappaBzeta. Nature 430: 218-222, 2004.

17. Krappmann D: Shaping oncogenic NF- $\kappa \mathrm{B}$ activity in the nucleus. Blood 122: 2146-2147, 2013.

18. Coto-Segura P, Gonzalez-Lara L, Batalla A, Eiris N, Queiro R and Coto E: NFKBIZ and CW6 in adalimumab response among psoriasis patients: Genetic association and alternative transcript analysis. Mol Diagn Ther 23: 627-633, 2019. 
19. Kim Y, Lee YS, Yang JY, Lee SH, Park YY and Kweon MN: The resident pathobiont Staphylococcus xylosus in Nfkbiz-deficient skin accelerates spontaneous skin inflammation. Sci Rep 7: 6348, 2017.

20. Sangil A, Arranz MJ, Guerri-Fernandez R, Perez M, Monzon H, Payeras A, Andres M, Torviso J, Ibanez L, Garau J and Calbo E: Genetic susceptibility to invasive pneumococcal disease. Infect Genet Evol 59: 126-131, 2018.

21. Kerami Z, Duijvis NW, Vogels EW, van Dooren FH, Moerland PD and Te Velde AA: Effect of interleukin-17 on gene expression profile of fibroblasts from Crohn's disease patients. J Crohns Colitis 8: 1208-1216, 2014.

22. Brennenstuhl H, Armento A, Braczysnki AK, Mittelbronn M and Naumann $\mathrm{U}: \mathrm{I} \kappa \mathrm{B} \zeta$, an atypical member of the inhibitor of nuclear factor kappa B family, is induced by Y-irradiation in glioma cells, regulating cytokine secretion and associated with poor prognosis. Int J Oncol 47: 1971-1980, 2015.

23. van Kester MS, Borg MK, Zoutman WH, Out-Luiting JJ, Jansen PM, Dreef EJ, Vermeer MH, van Doorn R, Willemze R and Tensen CP: A meta-analysis of gene expression data identifies a molecular signature characteristic for tumor-stage mycosis fungoides. J Invest Dermatol 132: 2050-2059, 2012.

24. Kakiuchi N, Yoshida K, Uchino M, Kihara T, Akaki K, Inoue Y, Kawada K, Nagayama S, Yokoyama A, Yamamoto S, et al: Frequent mutations that converge on the NFKBIZ pathway in ulcerative colitis. Nature 577: 260-265, 2020.

25. Jiang BH and Liu LZ: PI3K/PTEN signaling in angiogenesis and tumorigenesis. Adv Cancer Res 102: 19-65, 2009.

26. Wang X, Huang H and Young KH: The PTEN tumor suppressor gene and its role in lymphoma pathogenesis. Aging (Albany NY) 7: 1032-1049, 2015.

27. Carracedo A and Pandolfi PP: The PTEN-PI3K pathway: Of feedbacks and cross-talks. Oncogene 27: 5527-5541, 2008.

28. Yang X, Cheng Y, Li P, Tao J, Deng X, Zhang X, Gu M, Lu Q and Yin C: A lentiviral sponge for miRNA-21 diminishes aerobic glycolysis in bladder cancer T24 cells via the PTEN/PI3K/AKT/mTOR axis. Tumour Biol 36: 383-391, 2015.

29. Zununi Vahed S, Barzegari A, Rahbar Saadat Y, Goreyshi A and Omidi Y: Leuconostoc mesenteroides-derived anticancer pharmaceuticals hinder inflammation and cell survival in colon cancer cells by modulating NF- $\kappa \mathrm{B} / \mathrm{AKT} / \mathrm{PTEN} / \mathrm{MAPK}$ pathways. Biomed Pharmacother 94: 1094-1100, 2017.

30. Zhou W, Fu XQ, Zhang LL, Zhang J, Huang X, Lu XH, Shen L, Liu BN,Liu J,LuoHS, etal:The AKT1/NF-kappaB/Notch1/PTEN axis has an important role in chemoresistance of gastric cancer cells. Cell Death Dis 4: e847, 2013.

31. Yang Z, Fang S, Di Y, Ying W, Tan Y and Gu W: Modulation of NF- $\kappa \mathrm{B} / \mathrm{miR}-21 / \mathrm{PTEN}$ pathway sensitizes non-small cell lung cancer to cisplatin. PLoS One 10: e0121547, 2015.

32. Sobin LH, Gospodarowicz MK and Wittekind C (eds); UICC International Union Against Cancer: TNM Classification of Malignant tumors. 7th edition. Wiley-Blackwell, pp262-265, 2009.

33. Sauter G, Algaba F, Amin MB, Busch C, Cheville J, Gasser T, Grignon D, Hofstaedter F, Lopez-Beltran A and Epstein J: Tumours of the urinary system: Non-invasive urothelial neoplasias. In: World Health Organization Classification of Tumours: Pathology and Genetics of Tumours of the Urinary System and Male Genital Organs. Eble JN, Sauter G, Epstein JI and Sesterhenn I (eds). IARC Press, Lyon, pp89-157, 2004.

34. Livak KJ and Schmittgen TD: Analysis of relative gene expression data using real-time quantitative PCR and the 2(-Delta Delta C(T)) method. Methods 25: 402-408, 2001.

35. Yang K, Xiao Y, Xu T, Yu W, Ruan Y, Luo P and Cheng F: Integrative analysis reveals CRHBP inhibits renal cell carcinoma progression by regulating inflammation and apoptosis. Cancer Gene Ther 27: 607-618, 2020.

36. Ersahin T, Tuncbag N and Cetin-Atalay R: The PI3K/AKT/mTOR interactive pathway. Mol Biosyst 11: 1946-1954, 2015.

37. Kluth LA, Black PC, Bochner BH, Catto J, Lerner SP, Stenzl A, Sylvester R, Vickers AJ, Xylinas E and Shariat SF: Prognostic and prediction tools in bladder cancer: A comprehensive review of the literature. Eur Urol 68: 238-253, 2015.
38. Ishiguro-Oonuma T, Ochiai K, Hashizume $\mathrm{K}$ and Morimatsu M: The role of IFN- $\gamma$ in regulating Nfkbiz expression in epidermal keratinocytes. Biomed Res 36: 103-107, 2015.

39. Muromoto R, Tawa K, Ohgakiuchi Y, Sato A, Saino Y, Hirashima K, Minoguchi H, Kitai Y, Kashiwakura JI, Shimoda K,

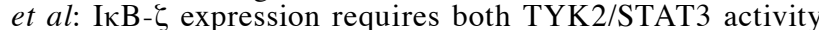
and IL-17-regulated mRNA stabilization. Immunohorizons 3: $172-185,2019$.

40. Coussens LM and Werb Z: Inflammation and cancer. Nature 420: 860-867, 2002.

41. Keniry M and Parsons R: The role of PTEN signaling perturbations in cancer and in targeted therapy. Oncogene 27: 5477-5485, 2008.

42. Puzio-Kuter AM, Castillo-Martin M, Kinkade CW, Wang X, Shen TH, Matos T, Shen MM, Cordon-Cardo C and Abate-Shen C: Inactivation of p53 and Pten promotes invasive bladder cancer. Genes Dev 23: 675-680, 2009.

43. Tamura M, Gu J, Tran H and Yamada KM: PTEN gene and integrin signaling in cancer. J Natl Cancer Inst 91: 1820-1828, 1999.

44. Corti F, Nichetti F, Raimondi A, Niger M, Prinzi N, Torchio M, Tamborini E, Perrone F, Pruneri G, Di Bartolomeo M, et al: Targeting the PI3K/AKT/mTOR pathway in biliary tract cancers: A review of current evidences and future perspectives. Cancer Treat Rev 72: 45-55, 2019.

45. Ediriweera MK, Tennekoon KH and Samarakoon SR: Role of the PI3K/AKT/mTOR signaling pathway in ovarian cancer: Biological and therapeutic significance. Semin Cancer Biol 59: 147-160, 2019.

46. Xing X, Zhang L, Wen X, Wang X, Cheng X, Du H, Hu Y, Li L, Dong B, Li Z and Ji J: PP242 suppresses cell proliferation, metastasis, and angiogenesis of gastric cancer through inhibition of the PI3K/AKT/mTOR pathway. Anticancer Drugs 25: 1129-1140, 2014.

47. Sathe A and Nawroth R: Targeting the PI3K/AKT/mTOR pathway in bladder cancer. Methods Mol Biol 1655: 335-350, 2018.

48. Hou T, Zhou L, Wang L, Kazobinka G, Zhang X and Chen Z: CLCA4 inhibits bladder cancer cell proliferation, migration, and invasion by suppressing the PI3K/AKT pathway. Oncotarget 8: 93001-93013, 2017.

49. Li Z, Hong S and Liu Z: IncRNA LINC00641 predicts prognosis and inhibits bladder cancer progression through miR-197-3p/KLF10/PTEN/PI3K/AKT cascade. Biochem Biophys Res Commun 503: 1825-1829, 2018.

50. Zhang XG, Zhang T, Li CY, Zhang MH and Chen FM: CD164 promotes tumor progression and predicts the poor prognosis of bladder cancer. Cancer Med 7: 3763-3772, 2018.

51. Li JY, Huang WX, Zhou X, Chen J and Li Z: Numb inhibits epithelial-mesenchymal transition via RBP-JK-dependent Notch1/PTEN/FAK signaling pathway in tongue cancer. BMC Cancer 19: 391, 2019.

52. Li X, Dai Y and Xu J: miR-21 promotes pterygium cell proliferation through the PTEN/AKT pathway. Mol Vis 24: 485-494, 2018.

53. Qin J, Fu M, Wang J, Huang F, Liu H, Huangfu M, Yu D, Liu H, Li X, Guan X and Chen X: PTEN/AKT/mTOR signaling mediates anticancer effects of epigallocatechin-3-gallate in ovarian cancer. Oncol Rep 43: 1885-1896, 2020.

54. Augello G, Puleio R, Emma MR, Cusimano A, Loria GR, McCubrey JA, Montalto G and Cervello M: A PTEN inhibitor displays preclinical activity against hepatocarcinoma cells. Cell Cycle 15: 573-583, 2016.

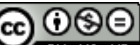

This work is licensed under a Creative Common Attribution-NonCommercial-NoDerivatives 4.0 International (CC BY-NC-ND 4.0) License. 